\title{
Hantavirosis: Caracterización clínica-epidemiológica de pacientes pediátricos en Chile
}

\author{
Marcela Ferrés G., Carmen Sandoval C., Iris Delgado B., \\ Viviana Sotomayor P., Andrea OLea N. y Pablo A. Vial C.
}

\begin{abstract}
Pontificia Universidad Católica de Chile, Santiago Departamento de Pediatría y Laboratorio de Infectología y Virología Molecular (MFG, CSC) Clínica Alemana Universidad del Desarrollo, Santiago, Instituto de Ciencias e Instituto de Epidemiología y Políticas de Salud (IDB)

Facultad de Medicina (PVC) Ministerio de Salud de Chile Departamento de Epidemiología (VSP, AON)

Proyecto Hantavirus: Ecología y Enfermedad en Chile (MFG, IDB,

PVC).
\end{abstract}

Los autores declaran no tener

conflictos de interés Financiamiento parcial a través de Proyecto Hantavirus Ecologia y Enfermedad en Chile. US Public Health

Service (grant Al 45452).

Recibido: 14 de julio de 2009 Aceptado: 6 de noviembre de 2009

Correspondencia a: Marcela Ferrés Garrido mferres@med.puc.cl

\section{Introducción}

\section{L} os primeros casos del síndrome cardiopulmonar por hantavirus (SCPH) fueron descritos en el suroeste de los Estados Unidos de Norte América (E.U.A.) en $1993^{1-5}$. Desde entonces, en E.U.A. se han descrito sobre 465 casos (a mayo 2007), de los cuales sólo una baja proporción ( $8 \%$ ) afecta a pacientes en edad pediátrica (bajo 15 años de edad). En Chile y Argentina, donde se han notificado sobre 1.500 casos de esta enfermedad desde 1995 al 2008, los casos pediátricos representan alrededor de $15 \%$ del total y la letalidad observada en ellos oscila entre 30 y $35 \% \%^{6-8}$.

$\mathrm{El}$ agente etiológico del SCPH es un virus ARN segmentado que pertenece a la familia de los Bunyavirida $e^{9,10}$. Los virus Sin Nombre (VSN) y virus Andes (VAND) son los agentes causales más frecuentes de SCPH en E.U.A. y en Argentina y Chile, respectivamente ${ }^{1,2,9,10}$. El reservorio natural de este virus son roedores silvestres, específicamente Peromyscus maniculatus o ratón venado para el VSN, en Norte América y Oligoryzomis longicaudatus o ratón colilargo, para el VAND, en Chile y Argentina. El virus se transmite al hombre a través de la inhalación de partículas virales presentes en fluidos del roedor: orina, deposiciones o saliva. Estos fluidos corporales del roedor pueden ser transformados en aerosoles por el hombre, inadvertidamente, durante actividades laborales, domésticas o recreativas. De esta manera, el virus ingresa al tracto respiratorio, punto de partida del ciclo infeccioso ${ }^{11-13}$.

La transmisión del virus desde una persona a otra es una vía de contagio descrita sólo para el VAND, sin que se haya establecido este tipo de transmisión para el VSN ${ }^{14-27}$. Su existencia se fundamenta en dos líneas de evidencia: la primera es la presentación de casos en conglomerados en Argentina y Chile. En nuestro país, $17 \%$ de los casos se presentan de esta forma, mientras que su ocurrencia es infrecuente en E.U.A. y Canadá, ${ }^{6,15,27}$. La segunda es la observación de que el riesgo global de la ocurrencia de un segundo caso de $\mathrm{SCPH}$ en un grupo familiar es de $3,4 \%$. Este riesgo entre los contactos cercanos de un caso índice fue diez veces mayor (17\%) en las parejas sexuales que el de otros individuos que vivían bajo el mismo techo $(1,7 \%)^{19}$. Los estudios de los casos en conglomerados en Argentina ${ }^{15,18}$ y un estudio prospectivo de los contactos de múltiples agrupaciones de casos en Chile $^{19}$, sugieren que, aquellos casos que ocurren mediando un intervalo 
de dos o más semanas, son probablemente producidos por transmisión de persona a persona, más que a partir de una fuente ambiental. El virus parece transmitirse durante la fase prodrómica de la enfermedad, cuando un contacto estrecho y prolongado ha ocurrido entre los casos índices y sus contactos, por ejemplo aquellos que han compartido saliva o secreciones respiratorias ${ }^{18,19}$. Tres de estos estudios en Argentina han mostrado, además de las evidencias epidemiológicas, evidencias de virología molecular que sostienen la transmisión persona a persona ${ }^{15,16,18}$.

En Chile, se han confirmado 584 casos de SCPH hasta diciembre del 2007, incluyendo pacientes con manifestaciones leves y graves de la enfermedad. La edad promedio de los casos fluctúa entre menos de uno y 76 años (promedio de 32 años) y la letalidad global es de $36 \%$ (209 casos fallecidos $)^{6}$.

La infección es endémica, con brotes estacionales iniciados a fines de primavera, presentándose la mayoría de los casos entre los meses de abril y noviembre. Se han notificado casos desde la Región de Valparaíso hasta la Región de Aysén (entre $32^{\circ}$ y $48^{\circ}$ latitud sur), distribuyéndose la mayoría de ellos entre las regiones del Bío-Bío y de Aysén ${ }^{6,17}$.

La frecuencia de notificación en personas bajo 15 años de edad, es aproximadamente de $15 \%{ }^{6,17}$. Este porcentaje es dos veces superior al observado entre los casos de SCPH por VSN; considerando que las propiedades de virulencia propias del agente y las características genéticas de la población son similares en un área geográfica determinada, es probable que la mayor frecuencia observada en niños se relacione a los factores de riesgo asociados a la adquisición de la infección.

La presentación clínica de la infección por ambos virus es similar ${ }^{6,17}$. La infección por VAND produce un cuadro clínico caracterizado por fiebre asociada a síntomas inespecíficos como cefalea, mialgias, calofríos, malestar general, síntomas gastrointestinales y, en una proporción de los casos, es seguido por una insuficiencia respiratoria y shock cardiogénico (síndrome cardiopulmonar). Adicionalmente, el virus puede producir compromiso de otros sistemas, evolucionando con coagulopatía, insuficiencia renal, hepatitis y pancreatitis.

El conocimiento por parte del equipo de salud de las características epidemiológicas y clínicas de los casos pediátricos en Chile son factores de alta importancia para el reconocimiento clínico precoz y la identificación de las situaciones de riesgo prevenibles, constituyéndose en el principal objetivo de este trabajo.

\section{Pacientes y Método}

El estudio contempló el análisis descriptivo de la información epidemiológica y clínica de los casos pediátricos (igual o menores de 15 años), notificados al Ministerio de Salud (MINSAL) de Chile entre los años 1997 y 2007. La información se obtuvo a través de una encuesta epidemiológica que incluyó 110 variables, entre ellas: edad, sexo, lugar probable de contagio, actividades de riesgo ambiental, contacto con otros casos, pertenencia a un conglomerado, duración del período prodrómico, compromiso clínico de la enfermedad, sobrevida. Para efectos de clasificar la evolución clínica, el MINSAL distingue dos grupos: "grave" (con inestabilidad hemodinámica) y "no grave" (sin alteraciones hemodinámicas $)^{17}$.

Entre los pacientes pediátricos notificados al MINSAL, se estudió una cohorte de niños en los que se obtuvo y se revisó las fichas clínicas o los formularios de registro clínico disponibles del proyecto "Hantavirus: Ecología y Enfermedad en Chile", analizándose factores epidemiológicos, presentación clínica y análisis de laboratorio. Para facilitar la clasificación y hacerla más descriptiva del pronóstico clínico hemos utilizado una división arbitraria en tres categorías: leve (paciente sólo utiliza oxígeno), moderado (paciente en ventilación mecánica) y severo (paciente en ventilación mecánica y shock cardiogénico) ${ }^{31}$.

Análisis estadístico. Incluyó descripción de frecuencias y tablas de contingencias. La significancia estadística se verificó a través de prueba exacta de Fisher y $\chi^{2}$ para las variables categóricas. Para las variables continuas se utilizó la prueba de ANOVA. Se consideró significancia estadística para $\mathrm{p}<0,05$. Los análisis se realizaron con el programa estadístico SPSS 15.0.

\section{Resultados}

\section{Análisis descriptivo de pacientes pediátricos notificados al MINSAL}

Un total de 82 niños fueron notificados con infección por hantavirus al MINSAL durante el período analizado y correspondió al 15\% del total de casos notificados en el país (82/546) a diciembre del 2007.

Distribución por género: $58,5 \%$ de los casos pediátricos correspondió al sexo masculino (48/82); en la población de casos sobre 15 años de edad, $81 \%$ fue de sexo masculino $(\mathrm{p}<0,001)$.

Edad: De los 82 niños, 22\% de los casos tenía entre 6 semanas y 5 años de edad, $23 \%$ entre 6 y 10 años de edad y $55 \%$ tenía entre 11 y 15 años. El promedio de edad del grupo fue de 9,8 años (DE 4,2); la edad promedio de los niños superó en dos años a la edad de las niñas $(\mathrm{p}=0,056)$.

Distribución geográfica: 79,2\% (n: 65) de los casos se concentró entre los paralelos $36^{\circ} 00^{\prime}$ y $44^{\circ} 14^{\prime}$ latitud sur, correspondientes a las regiones de Bío-Bío, Arauco, Los Ríos y los Lagos. La mayoría (98\%) de ellos contrajo la enfermedad en un ambiente rural y, en sólo dos casos, la encuesta epidemiológica concluyó que la exposición se produjo en una zona urbana. 


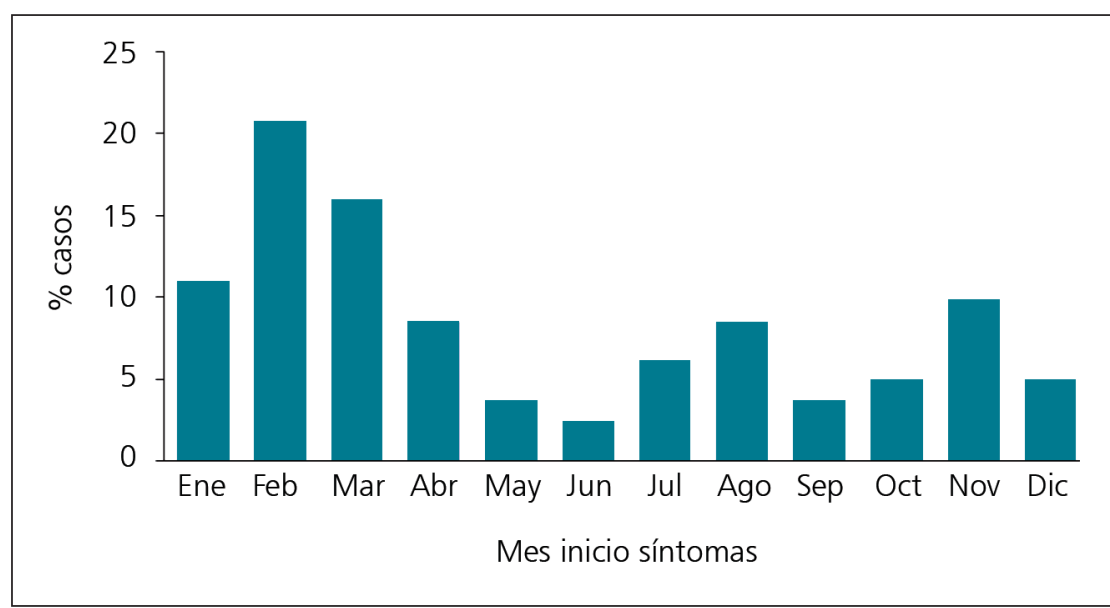

Figura 1. Distribución de casos SCPH pediátricos confirmados según mes de ocurrencia.



Figura 2. Síntomas y signos más frecuentes presentes en 24 niños con síndrome cardiopulmonar por hantavirus. Chile 1997-2007.

Estacionalidad: la notificación de casos a lo largo de los diez años analizados mostró que $66 \%$ se presentó entre noviembre y abril. En el mes de febrero se notificó un quinto de todos los casos de la temporada que incluye el período de vacaciones escolares en Chile (Figura 1); sin embargo, $25 \%$ de los casos pediátricos se siguieron presentando durante los meses más fríos, entre mayo y septiembre.

Presentación en conglomerados: el 20,7\% (17/82) del total de niños con SCPH se presentó dentro de un grupo familiar, en que dos o más de sus miembros sufrieron la enfermedad. La edad promedio de estos niños fue menor que la del grupo general ( 7,4 años versus 9,8 años) ( $p<$ $0,05)$.

El $82,3 \%(14 / 17)$ de ellos fueron casos adicionales (segundo o tercer caso) y sólo tres correspondieron a casos índices (o primer caso en el hogar).

La letalidad observada en los casos pediátricos que se presentaron en conglomerados fue de 35,3 versus $37 \%$ en los casos aislados $(\mathrm{p}=\mathrm{NS})$.

Evolución de la enfermedad, hospitalización y gravedad. De los 82 pacientes notificados, 60 (77\%) se clasificaron como de evolución grave y 18 (23\%) no grave, en cuatro no se registró la información. El 50\% de los pacientes graves fallecieron y no se registro muerte alguna entre los no graves $(\mathrm{p}=0,001)$, indicando que la presencia de shock es un importante factor pronóstico.

El tiempo transcurrido entre el inicio de los síntomas y la primera consulta médica fue en promedio de 2,6 días (0 a 11 días, D.E. 2,18), y desde el inicio de los síntomas prodrómicos a la hospitalización de 4,2 días ( 0 a 12 días, DE 2,27).

Los pacientes que evolucionaron en forma grave no consultaron más tarde que los que tuvieron una evolución leve, en promedio 2,5 días versus 3 días $(\mathrm{p}=\mathrm{ns})$.

Entre los pacientes fallecidos, $60 \%$ (18/30) consultó el primer día en que sus padres notaron la presencia de síntomas, y fueron hospitalizados de inmediato o hasta cuatro días después de la primera consulta. Este plazo no fue diferente al consignado en los niños que no fallecieron ( $\mathrm{p}=\mathrm{ns})$.

El $77 \%$ de los pacientes graves falleció dentro de las primeras 24 horas de ingreso al hospital, siendo el promedio de estadía hospitalaria en este grupo de 1,2 días (rango 0 a 8 días).

La letalidad global del SCPH en niños fue de $36,6 \%$ (30/82). No se observaron diferencias significativas por sexo, $38 \%$ en mujeres y $35 \%$ en varones. La edad promedio de los fallecidos, como la de los sobrevivientes, fue de 9 y 10 años respectivamente. La mayor proporción de niños fallecidos se encontró en el grupo etario de 0 a 10 años, no siendo esta diferencia estadísticamente significativa al ser comparado con el grupo de niños mayores (11 a 15 años) $(\mathrm{p}=0,27)$.

\section{Análisis de pacientes con registro clínico disponible}

Se tuvo acceso a los registros de la historia clínica en 24 niños. De estos pacientes, 62\% (15/24) se presentó como SCPH grave y 29\% (7/24) cursó con SCPH leve. En dos sobrevivientes no se logró obtener el dato de gravedad de su enfermedad. Al igual que el universo total, todos los pacientes que fallecieron se presentaron como clínicamente graves (con insuficiencia respiratoria y shock). La letalidad global de este grupo de niños fue de $29 \%$ (7/24).

El período de incubación estimado fue, en promedio, de 18 días ( 6 a 43 días). Los pacientes que fallecieron los hicieron, en promedio, 7,8 días tras iniciarse los síntomas y 1,3 días luego de su hospitalización. 
Tabla 1. Descripción de 24 pacientes pediátricos diagnosticados con síndrome cardiopulmonar por hantavirus. Chile 1997-2002

\begin{tabular}{|c|c|c|c|c|c|c|c|}
\hline Caso/sexo & $\begin{array}{l}\text { Edad } \\
\text { (años) }\end{array}$ & $\begin{array}{l}\text { Cluster/condición } \\
\text { en el cluster }\end{array}$ & $\begin{array}{l}\text { Período de } \\
\text { incubación } \\
\text { (días) }\end{array}$ & $\begin{array}{l}\text { Intervalo síntomas/ } \\
\text { hospitalización } \\
\text { (días) }\end{array}$ & Gravedad & Desenlace & Actividad riesgo \\
\hline $1 / F$ & 2 & Si/adicional & 6 & 15 & Leve & Vive & $\begin{array}{l}\text { Duerme con su padre que se encontraba cursan- } \\
\text { do con SCPH en fase prodrómica }\end{array}$ \\
\hline $2 / \mathrm{M}$ & 10 & Si/adicional & $20-39$ & 3 & Grave & Fallece & $\begin{array}{l}\text { Participa en desarme vivienda en zona rural y } \\
\text { contacto con dos casos de SCPH }\end{array}$ \\
\hline $3 / \mathrm{M}$ & 6 sem & No & 43 & 1 & Grave & Vive & $\begin{array}{l}\text { Ingresa a casa cerrada en zona rural donde } \\
\text { se encontraron fecas de roedores y actividad } \\
\text { recreativa con sus padres }\end{array}$ \\
\hline $4 / \mathrm{M}$ & 13 & No & 27 & 4 & Grave & Vive & Actividad recreativa, duerme en galpón \\
\hline $5 / F$ & 15 & No & $22-29$ & 5 & Grave & Vive & $\begin{array}{l}\text { Carga leña en región precordillera Región de } \\
\text { Talca }\end{array}$ \\
\hline $6 / \mathrm{M}$ & 15 & No & $6-16$ & 7 & Grave & Fallece & Actividad recreativa campamento scout \\
\hline $7 / \mathrm{M}$ & 1 & $\begin{array}{l}\text { Si/adicional a su } \\
\text { padre }\end{array}$ & $4-21$ & 4 & Grave & Vive & $\begin{array}{l}\text { Ambiente contaminado y contacto con su padre } \\
\text { que falleció por SCPH }\end{array}$ \\
\hline $8 / \mathrm{M}$ & 12 & Si/adicional & 26 & 8 & Leve & Vive & $\begin{array}{l}\text { Ingresa a ambiente contaminado desde una } \\
\text { zona urbana, contacto con enfermos de SCPH }\end{array}$ \\
\hline $9 / \mathrm{M}$ & 5 & Si/adicional & 12 & 5 & Grave & Fallece & $\begin{array}{l}\text { Ingresa a limpiar casa deshabitada con su madre } \\
\text { que también enfermó }\end{array}$ \\
\hline $10 / F$ & 9 & No & 20 & 3 & $\mathrm{Nd}$ & Vive & Ingresa a casa deshabitada \\
\hline $11 / \mathrm{M}$ & 13 & No & 20 & 2 & Grave & Vive & Actividad recreativa e ingresa a bodega \\
\hline $12 / \mathrm{M}$ & 2 & Si/Primer caso & 10 & 9 & Grave & Vive & Ingresa a casa deshabitada \\
\hline $13 / \mathrm{M}$ & 5 & Si/adicional & 20 & 3 & Grave & Fallece & Actividad agrícola/desmalezamiento \\
\hline $14 / \mathrm{M}$ & 5 & No & 7 & 3 & Leve & Vive & Ingresa a galpón \\
\hline $15 / \mathrm{M}$ & 8 & No & 10 & 5 & $\mathrm{Nd}$ & Vive & Ingresa a bodega y casa deshabitada \\
\hline $16 / F$ & 10 & No & 15 & 3 & Grave & Fallece & Ingresa a casa deshabitada \\
\hline $17 / F$ & 13 & No & $\mathrm{Nd}$ & 5 & Leve & Vive & Actividad recreativa, visita quebrada \\
\hline $18 / \mathrm{M}$ & 9 & No & 21 & 3 & Grave & Fallece & Actividad recreativa en alrededores de un río \\
\hline $19 / \mathrm{M}$ & 8 & No & $\mathrm{Nd}$ & 5 & Leve & Vive & Reside en sector rural \\
\hline $20 / \mathrm{M}$ & 15 & No & $\mathrm{Nd}$ & 4 & Leve & Vive & Excursionista \\
\hline $21 / \mathrm{M}$ & 13 & No & $\mathrm{Nd}$ & 7 & Grave & Vive & Reside en sector rural \\
\hline $22 / \mathrm{M}$ & 14 & No & $\mathrm{Nd}$ & 5 & Grave & Vive & Reside en sector rural \\
\hline $23 / F$ & 12 & No & $\mathrm{Nd}$ & 13 & Grave & Fallece & Reside en sector rural \\
\hline $24 / F$ & 13 & No & $\mathrm{Nd}$ & $\mathrm{Nd}$ & Leve & Vive & Recreativa \\
\hline
\end{tabular}


Los factores de riesgo a los que se expusieron se muestran en la Tabla 1.

Los síntomas más frecuentemente presentados al inicio del cuadro clínico, se grafican en la Figura 2.

Con respecto a aquellos pacientes que cursaron graves en su evolución (n: 15) la mitad requirió ventilación mecánica y apoyo con fármacos vasoactivos. Los pacientes que debieron hospitalizarse en UCI estuvieron, en promedio, 3,5 días; no pudimos acceder a datos de su evolución.

\begin{tabular}{|c|c|c|}
\hline $\begin{array}{l}\text { Resultados de laboratorio } \\
\text { día } 1\end{array}$ & $\begin{array}{l}\text { Pacientes } \\
\text { fallecidos }\end{array}$ & $\begin{array}{c}\text { Pacientes } \\
\text { sobrevivientes }\end{array}$ \\
\hline Hematocrito (\%) & 49 & 42 \\
\hline Leucocitos $/ \mathrm{mm}^{3}$ & 29.500 & 20.274 \\
\hline Linfocitos inmunoblastos (\%) & No descritos & Descrito en 2 pacientes \\
\hline Baciliformes (\%) & 27 & 18 \\
\hline Plaquetas $/ \mathrm{mm}^{3}$ & 48.250 & 52.083 \\
\hline TP (segundos)/ TTPK (segundos) & $42 / 154$ & $77,8\left(^{*}\right) / 46,1\left(^{*}\right)$ \\
\hline Nitrógeno ureico (mg/dL) & 27 & 49 \\
\hline GOT (U/I)/ GPT(U/L) & $168 / 71$ & 283/192 \\
\hline Deshidrogenada láctica (U/L) & 766 & 1.279 \\
\hline Albúmina (gr/dL) & 2,3 & 2,7 \\
\hline $\mathrm{Na}^{+}(\mathrm{mg} / \mathrm{dL})$ & 129 & 124 \\
\hline$\left({ }^{*}\right): p=0,03$ & & \\
\hline
\end{tabular}

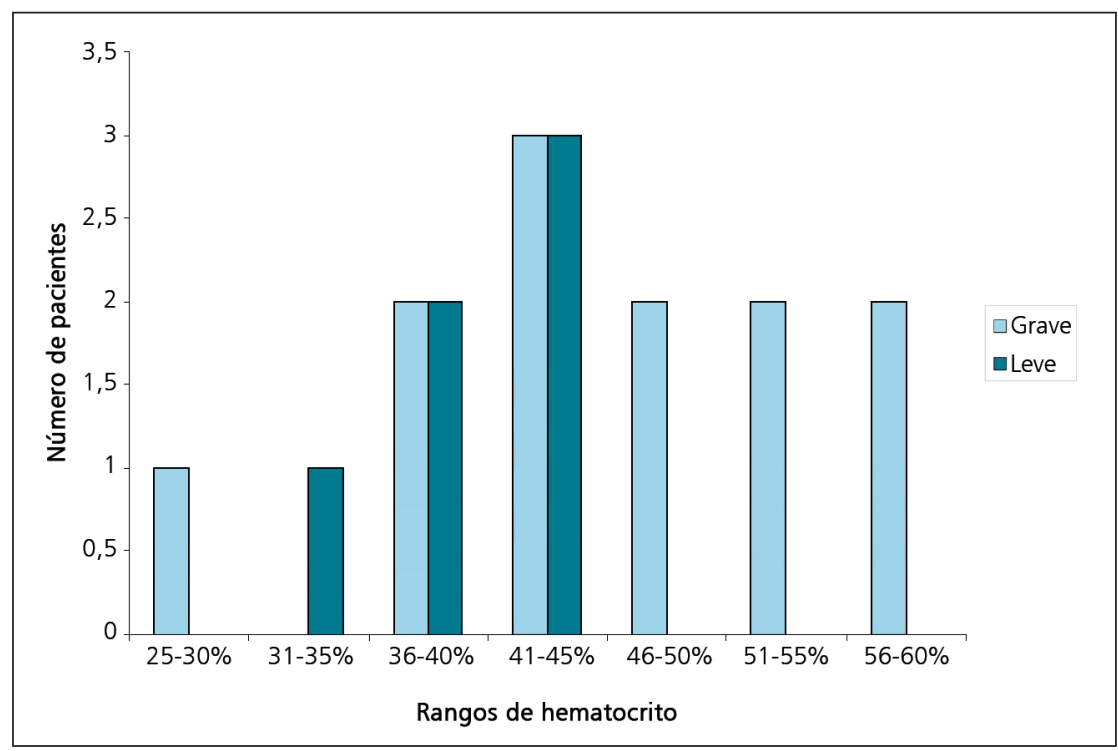

Figura 3. Valores de hematocrito alcanzados en pacientes con síndrome cardiopulmonar por hantavirus graves y leves. (n: 18). Chile 1997-2007. $p=0,024$.
Exámenes de laboratorio al ingreso: independiente del estado de gravedad o si fallecieron, todos presentaron leucocitosis, con desviación a izquierda marcada y trombocitopenia. Prácticamente hay ausencia de descripción de linfocitos con morfología de inmunoblastos. Otros elementos constantes fueron: hiponatremia, hipoalbuminemia, elevación de la LDH y transaminasas. (Tabla 2). Todos los pacientes tenían importantes alteraciones de las pruebas de coagulación (TP y TTPK) (Tabla 3); sin embargo, el deterioro de estos parámetros de laboratorio fue significativamente mayor entre los pacientes fallecidos $(p=0,03)$. Todos los pacientes que evolucionaron en forma grave presentaron hematocrito igual o sobre $46 \%$, no existiendo ningún paciente no grave que tuviera esta cifra $(\mathrm{p}=0,024)$ (Figura 3$)$.

\section{Discusión}

La infección por hantavirus en Chile es hoy un problema endémico; la magnitud del problema en la edad pediátrica ( $15 \%$ del total de casos) se manifestó en nuestros resultados en porcentaje similar a lo descrito en otras series, al igual que la letalidad $(36,6 \%)$, observada en los primeros diez años de reconocimiento de la enfermedad, es decir, de cada diez niños diagnosticados tres a cuatro fallecieron.

Los casos de SCPH en el hemisferio norte comparten las manifestaciones clínicas con los casos pediátricos chilenos. En la serie nacional presentada, la mitad tenía menos de 10 años de edad, mientras que en E.U.A. los casos reportados corresponden a niños sobre 10 años de edad $^{5,6}$. El paciente con menor edad notificado en Chile corresponde a un lactante de seis semanas que se infectó desde una fuente ambiental, probablemente en el período de recién nacido. La gran diferencia, única en el cono sur de Sur América, es que en Chile, alrededor de 17\% de los casos se presenta en conglomerados que afectan a dos a tres personas ${ }^{9,17-19,28}$, observándose en este contexto casos pediátricos ${ }^{29,30}$. En esta serie, este comportamiento se vio en $21 \%$ del total de casos, frecuencia levemente mayor a la estimación global de las referencias mencionadas.

La exposición a un ambiente contaminado con el virus es el principal mecanismo de adquisición de éste. La participación de los niños en actividades peridomésticas junto a sus padres, preferentemente en áreas rurales, pueden explicar los casos pediátricos en todos los grupos etarios. Sin embargo, la existencia de conglomerados en que haya niños como casos adicionales y que no haya habido una fuente clara de exposición ambiental sugiere que la vía de contagio pueda corresponder a una transmisión persona a persona ${ }^{14-27}$. Ejemplos de estas situaciones se observan en los casos de 1 y 2 (Figuras 4 y 5 ).

El hecho de que la distribución por sexo entre casos pediátricos y de adultos haya sido significativamente 


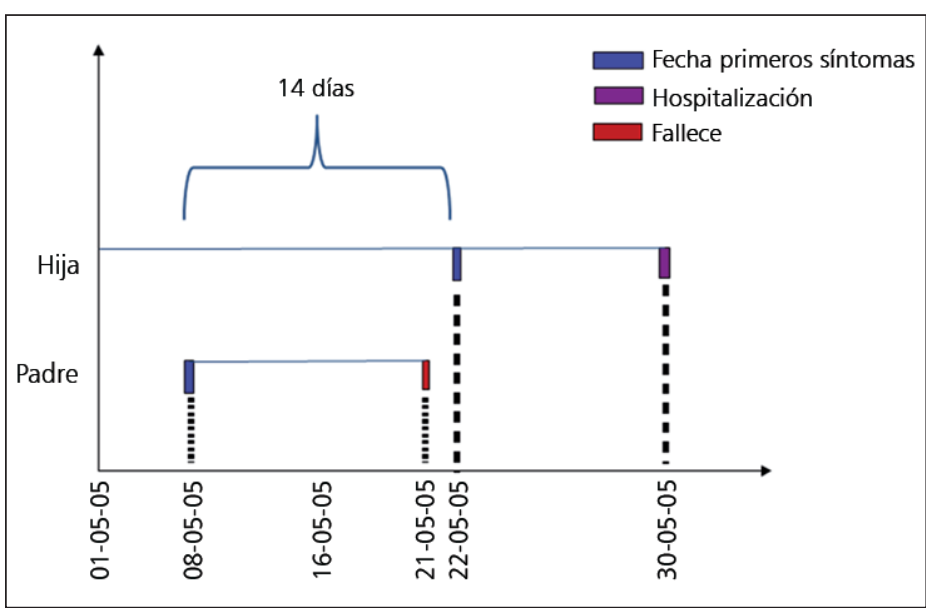

Figura 4. Síndrome cardiopulmonar por hantavirus. Patrón temporal de cluster 1.



Figura 5. Síndrome cardiopulmonar por hantavirus. Patrón temporal de cluster 2. diferente, sugiere que los factores de riesgo asociados a la adquisición de la infección difieren según el grupo etario. En la población adulta, la exposición laboral en faenas forestales, desmalezamiento y otras, representa uno de los principales factores de riesgo. En niños aparece con mayor frecuencia la exposición en actividades recreativas y el contacto con otros casos intrafamiliares.

La distribución geográfica de los casos pediátricos ha sido vasta, desde la Región Metropolitana hasta Aysén; sin embargo, es importante considerar que la extensión del hábitat de $O$. longicaudatus es aún mayor, desde el sur del valle de Copiapó hasta la Región de Magallanes ${ }^{32}$, habiéndose encontrado roedores infectados por el límite norte en el Parque Nacional Fray Jorge ( $30^{\circ} 38^{\prime}$ latitud sur) y por el sur en el sector de Fuerte Bulnes (53 $36^{\prime}$ latitud sur) (comunicación personal E. Palma).

La distribución estacional ha sido similar a la de la población general, con concentración de los casos en la temporada de verano, específicamente en febrero. Considerando que el período de incubación del VAND ha sido estimado en un rango de 7 a 39 días $^{33}$, con casos reportados después de 40 a 45 días post exposición ${ }^{17}$, es evidente que muchos de estos niños contrajeron el virus entre diciembre y enero cuando las actividades escolares han finalizado y se inician las actividades recreativas, familiares o grupales como campamentos de scouts. Esta temporada coincide también con el aumento, observado anualmente, de la población de roedores de la especie O. longicaudatus en áreas de transición urbano rurales.

Considerando entonces, que la distribución geográfica del reservorio es extensa y la temporalidad de presentación de los casos es durante todo el año, con alzas en los meses de verano, los esfuerzos en la difusión de contenidos educacionales preventivos ante conductas de riesgo, como de reconocimiento de los síntomas iniciales de la infección por hantavirus deben ser mantenidos amplia y constantemente en todo Chile.

El personal de salud tiene un rol fundamental en identificar precozmente los casos, debiendo tener una alta sospecha clínica de la enfermedad en aquellos pacientes que posean factores de riego para contraer la enfermedad, ya sea por actividades recreativas o laborales en que acompañan a un adulto, y frente a un paciente que estuvo en contacto con algún caso confirmado y/o adultos fallecidos de distress respiratorio agudo sin causa aparente. Debido a que una derivación oportuna a un centro que tenga unidad de cuidado intensivo, puede hacer la diferencia en el pronóstico de los niños afectados, el personal de salud debe tener, además, un bajo umbral al planteamiento del diagnóstico y ejecución de exámenes preliminares con el fin de lograr la atención óptima de estos pacientes ${ }^{34}$.

Hubo una rápida consulta frente al inicio de síntomas (promedio de 2,5 días), sugiriendo que los padres tuvieron una conducta activa con sus hijos frente a un problema de salud con características inespecíficas, como lo es el SCPH, hospitalizándose, en promedio, al cuarto día desde el inicio de sus síntomas. Ambas cifras no fueron significativamente distintas entre pacientes fallecidos y sobrevivientes.

Los síntomas cardinales para sospechar un SCPH son, en orden de frecuencia: fiebre y compromiso digestivo (náuseas, vómitos, dolor abdominal o diarrea), cefalea y mialgias, y compromiso respiratorio leve en la etapa inicial, pudiendo empeorar drásticamente en horas. Como apoyo de laboratorio, la disponibilidad de hemograma completo con recuento de plaquetas y observación de la morfología de inmunoblastos de los leucocitos es comentado en la literatura médica como de gran ayuda ${ }^{35}$; este útil indicador estuvo prácticamente ausente en los casos analizados. La hemoconcentración, expresada 
en un hematocrito elevado, se observa con frecuencia, especialmente en los casos graves, pero este fenómeno ocurre tardíamente, coincidiendo con la etapa de compromiso pulmonar, y no constituye un marcador precoz para el diagnóstico, pero sí un indicador importante del pronóstico de la enfermedad.

Las pruebas de coagulación muy alteradas, así como el hematocrito sobre $46 \%$, se asociaron en esta serie con letalidad y evolución grave, respectivamente.

La bibliografía revisada recomienda usar como herramienta inicial en la evaluación de los pacientes con sospecha de SCPH la presencia de cuatro de cinco elementos alterados en el hemograma: trombocitopenia, mielocitosis, hemoconcentración, ausencia de granulación tóxica en neutrófilos y más de $10 \%$ de linfocitos con morfología de inmunoblastos. Estos hallazgos tienen una sensibilidad de $96 \%$ y una especificidad del $99 \%$ para $\mathrm{SCPH}$, lo que puede entonces mejorar el ingreso precoz de estos pacientes a unidades de cuidados intensivos ${ }^{35}$.

No se logró establecer los factores de riesgo con mayor peso en predecir quienes son aquellos pacientes que pudieran presentar la enfermedad del universo de pacientes sospechosos, debido al número de casos; sin embargo, se observó una tendencia de factores más repetitivos entre los pacientes confirmados como son: ingresar con adultos a limpiar recintos abandonados, internarse en bosques/ matorrales, visitas a lugares rurales, contacto con caso confirmado, dormir bajo el mismo techo que un caso confirmado, participación en demolición o desarme de casa y manipulación de leña.

El índice de sospecha alcanzó, en esta serie, a 28\%, muy por debajo de lo observado en la población adulta que se encuentra alrededor de $75 \%$, importante cifra que motiva a continuar con la difusión del conocimiento de esta enfermedad, entregando herramientas útiles a la población y al personal de salud en vías de mejorar la sospecha clínica del SCPH en niños. La difusión de la información a todos los niveles, instituciones educacionales, deportivas y recreativas, municipales, así como a los encargados de la atención en salud irá en directo beneficio de nuestros pacientes en edad pediátrica.

La infección por hantavirus en Chile seguirá siendo un desafío en prevención, diagnóstico certero, precoz, búsqueda de terapias paliativas o etiológicas.
Agradecimientos a: Departamento de Epidemiología, MINSAL. Proyecto Hantavirus: Ecología y Enfermedad en Chile. Dres. Raúl Bustos, Hospital Regional de Concepción Guillermo Grant Benavente; Marta Werner, Departamento de Epidemiología, Región del Bío Bío; Jury Hernández, Hospital Víctor Ríos Ruiz, Los Ángeles, Región del Bío-Bío; Mario Calvo, Maritza Navarrete y Rita Mansilla, Hospital Regional Valdivia y Departamento de Epidemiología, Región de los Ríos; Mauricio Tapia y Marco Acuña, Hospital Regional de Coyhaique y Departamento de Epidemiología XI Región; Alejandro Donoso y José León, Hospital Padre Hurtado, Santiago; Eduardo Ferreiro, Hospital San Borja Arriarán, Santiago. A Claudia Marco, Proyecto Hantavirus: Ecología y Enfermedad y a Jaime Cerda, Departamento de Salud Pública, Pontificia Universidad Católica de Chile, por la lectura crítica en los primeros análisis de este trabajo.

\section{Resumen}

Introducción: Los primeros casos del síndrome cardiopulmonar por hantavirus en población pediátrica fueron descritos en Estados Unidos de América y representaron $8 \%$ de los casos comunicados; en Chile la frecuencia relativa en niños ha sido de $15 \%$ del total nacional. Objetivo: Describir la epidemiología y evolución clínica de 82 niños notificados al MINSAL hasta el 2007 y caracterizar el comportamiento clínico en 24 de ellos de quienes se disponía de registro clínico detallado. Resultados: Cuarenta pacientes tenían bajo 10 años de edad, predominando en varones. Un quinto (17/82) estuvo asociado a conglomerados familiares. Noventay ocho por ciento (80/82) se presentaron en áreas rurales y $54(66 \%)$ ocurrieron en el verano. La letalidad fue de $36,6 \%$. Los síntomas más frecuentes fueron: fiebre (93\%), dificultad respiratoria $(75 \%)$ y síntomas gastrointestinales $(75 \%)$. De los exámenes de laboratorio con significancia estadística, las pruebas de coagulación alteradas predicen fallecimiento y el hematocrito elevado está siempre presente en pacientes graves. Conclusión: El diagnóstico oportuno facilita el tratamiento intensivo precoz. La difusión de la presentación clínica infantil mejorará la sospecha diagnóstica en el personal de salud.

\section{Referencias}

1.- Centers for Disease Control and Prevention (CDC). Outbreak of acute illness-southwestern United States, 1993. MMWR Morb Mortal Wkly Rep 1993 Jun 11; 42 (22): 421-4.

2.- Duchin J S, Koster F T, Peters C J, Simpson G L, Tempest B, Zaki S R, et al. Hantavirus Pulmonary Syndrome: a clinical description of 17 patients with a newly recognized disease. The Hantavirus Study Group. N Engl J Med 1994; 330 (14): 949-55.

3.- Overturf G D. Clinical Sin Nombre hantaviral infections in children. Pediatr Infect Dis J 2005; 24 (4): 373-4.

4.- Ramos M M, Overtuf F D, Crowley M R, Rosemberg R B, Hjelle B. Infection with Sin Nombre hantavirus: clinical presentation and outcome in children and adolescents. Pediatrics 2001; 108 (2): E27.

5.- Ramos M M, Hjelle B, Overtuf F D. Sin Nombre hantavirus diseases in a ten-years-old boy and his mother. Pediatr Infect Dis J 2000; 19 (3): 248-50.

6.- MINSAL. Situación epidemiológica. http://epi. minsal.cl/epi/html/frames/frame12.htm. (accedido 03 enero 2009). 
7.- Lazaro M E, Resa A J, Barclay C M, Calanni L, Samengo L, Martínez L, et al. Hantavirus Pulmonary Syndrome in southern Argentina. Medicina (B Aires) 2000; 60 (3): 289-301.

8.- Pini N C, Resa A, Del Jesús Laime G, Lecot G, Ksiazek T G, Levis S, et al. Hantavirus infection in children in Argentina. Emerg Infect Dis 1998; 4 (1): 85-7.

9.- Toro J, Vega J D, Khan A S, Mills J N, Padula P, Terry W, et al. An outbreak of Hantavirus Pulmonary Syndrome, Chile, 1997. Emerg Infect Dis 1998; 4 (4): 687-94.

10.- Baró M, Vergara J, Navarrete M. Hantavirus in Chile: review and cases analyses since 1975. Rev Méd Chile 1999; 127 (12): 1513-23.

11.- López N, Padula P, Rossi C, Miguel S, Edelstein A, Ramirez E, et al. Genetic characterization and phylogeny of Andes virus and variants from Argentina and Chile. Virus Res 1997; 50 (1): 77-84.

12.- Galeno H, Mora J, Villagra E, Fernández J, Hernandez J, Mertz G, et al. First human isolate of hantavirus (Andes virus) in the Americas. Emerg Infect Dis 2002; 8 (7): 657-61.

13.- Tapia M, Mancilla C, Vera T M J. Hantavirus pulmonary syndrome, clinical experience in diagnosis and treatment. Hospital CoyhaiqueChile. Rev Chil Infectol 2000; 17 (3): 258-69.

14.- Lázaro M E, Cantoni G E, Calanni L M, Resa A J, Herrero E R, Iacono M A, et al. Clusters of hantavirus infection, Southern Argentina. Emerg Infect Dis 2007; 13 (1): 104-10.

15.- Padula P J, Edelstein A, Miguel S D, López N M, Rossi C M, Rabinovich R D. Hantavirus Pulmonary Syndrome outbreak in Argentina: Molecular evidence for person-toperson transmission of Andes virus. Virology 1998; (2): 323-30.

16.- Pinna D M, Martínez V D, Bellomo C M, López C, Padula P. New epidemiologic and molecular evidence of person to person transmission of hantavirus Andes Sout. Medicina
(B Aires) 2004; 64 (1): 43-6.

17.- Sotomayor V, Olea A, Labraña M. Diagnostic and treatment of cardiopulmonary syndrome. Chile-2007. Rev Chil Infectol 2009; 26 (1): 68-86.

18.- Martínez V P, Bellomo C M, San Juan J, Pinna D M, Forlenza R, Elder M, et al. Person-to-person transmission of Andes virus. Emerg Infect Dis. 2005; 11 (12): 1848-53.

19. - Ferrés M, Vial P, Marco C, Yáñez L, Godoy P, Castillo C, et al. Prospective evaluation of household contacts of persons with Hantavirus Cardiopulmonary Syndrome in Chile. J Infec Dis 2007; 195 (11): 1563-71. Epub 2007 Apr 16.

20.- Puerta H, Cantillo C, Mills J, Hjelle B, SalazarBravo J, Mattar S. The new world hantaviruses. Ecology and epidemiology of and emerging virus in Latin America. Medicina (B Aires). 2006; 66 (4): 343-56.

21.- Mertz G J, Hjelle B, Crowley M, Iwamoto G, Tomicic V, Vial P. Diagnosis and treatment of new world hantavirus infection. Curr Opin Infect Dis. 2006 Oct; 19(5): 437-42.

22.- Kahn A S, Kitsutani P T, Corneli A L. Hantavirus pulmonary syndrome in the Americas: the early years. Semin Respir Crit Care Med 2000; 21 (4): 313-22.

23.- Fabbri M, Maslow MJ. Hantavirus Pulmonary Syndrome in the United State. Curr Infect Dis. 2001; 3 (3): 258-65.

24.- Castillo C, Mardones J, Villagra E. Prevalence of hantavirus antibodies in the health care personnel in direct contact with patients whit hantavirus pulmonary syndrome in Temuco, Chile 1997 to 1998. Rev Méd Chile 2000; 128 (7): 735-9.

25.- Chaparro J, Vega J, Terry W, Vera J L, Barra B, Meyer R, et al. Assessment of person-to-person transmission of hantavirus pulmonary syndrome in a Chilean hospital setting. J Hosp Infect 1998; 40 (4): 281-5.

26.- Wells R M, Young J, Williams R J, Armstrong
L R, Busico K, Khan A S, et al. Hantavirus transmission in the United States. Emerg Infect Dis 1997; 3(3): 361-5.

27.- Vitek C R, Breiman R F, Ksiazek T G, Rollin P E, McLaughlin J C, Umland E T, et al. Evidence against person-to-person transmission of hantavirus to health care workers. Clin Infect Dis 1996; 22 (5): 824-6.

28.- Navarrete M, Saldías F, Mancilla M V R, Zaror L, Ferrés M. Evidencia clínico epidemiológica de la existencia del síndrome pulmonar por hantavirus en Valdivia Chile desde 1993. Rev Chil Infectol 2000; 17 (3): 233-40.

29.- Soza G, Lorca P, Puebla S, Wenzel M, Navarrete M, Villagra E, et al. Hantavirus pulmonary syndrome in children. Chile: IX and X Regions, 1998-2000. Rev Chil Infectol 2000; 17 (3); 248-57.

30.- Ferrés M, Vial P. Hantavirus infection in children. Curr Opin Pediatric 2004; 16 (1): 70-5.

31.- Vial P, Valdivieso F, Ferrés M. Manejo del paciente crítico con Síndrome Cardiopulmonar por Hantavirus. Primera edición. Santiago: Editorial Salesianos 2004; 1-140.

32.- Torres-Pérez F, Navarrete-Droguett J, Aldunate R, Yates T L, Mertz G S, Vial P A, Ferres M, et al. Peridomestic small mammals associated with confirmed cases of human hantavirus disease in southcentral Chile. Am J Trop Med Hyg 2004; 70 (3): 305-9.

33.- Vial P A, Valdivieso F, Mertz G, Castillo C, Belmar E, Delgado I, et al. Incubation period of hantavirus cardiopulmonary syndrome. Emerg Infect Dis 2006; 12 (8): 1271-3.

34.- Jenison S, Hjelle B, Simpson S, Hallin J, Feddersen L, Koster F. Hantavirus pulmonary syndrome: clinical, diagnostic, and virologic aspects. Semin Respir Infect 1995; 10 (4): 25969

35.- Koster F, Foucar K, Hjelle B, Scott A, Chong Y Y, Larson R, et al. Rapid presumptive diagnosis of hantavirus cardiopulmonary syndrome by peripheral blood smear review. Am J Clin Pathol 2001; 116 (5): 665-72. 